\title{
Carbon Dioxide Internal Cooling Technology of Extrusion Blow Moulding Production
}

\section{Brdlík Pavel, Martin Borůvka}

Faculty of Engineering Technology. Technical University of Liberec. Studentská 2, 464 17, Liberec. Czech Republic. Email: pavel.brdlik@tul.cz,martin.boruvka@tul.cz

The goal of every company is to be a successful producer. There are no easy ways because there are a lot of factors that have varying impacts on the final profit. One of the most significant factors is production time. If the processing phases of the production of polymer products are compared, cooling is clearly the most time-consuming. The reason lies in the poor thermal conductivity of polymers. Therefore is very important looking for the optimally way of cooling. One of the very interesting improvements of current production process is application of progressive internal cooling systems which using cold medium, such as deep-cooled air, the injection of a mixture of water droplets with pressurized air or the injection of liquefied inert gas $\left(\mathrm{CO}_{2}, \mathrm{~N}_{2}\right)$. When these internal cooling techniques are compared, it is clear that the highest production increasing is achieved by the technology injection liquefied gas. Although this technology has been known for some time, it has not been widely used until now. The reason for this could be some production restrictions and process disadvantages. The main goal of this paper is therefore focused on find out these limitations.

Keywords: Extrusion Blow Moulding, Internal Cooling, Calibration Pin, Carbon Dioxide.

\section{Acknowledgement}

This paper was prepared due to the financial support from Student Grant Contest project from the TUL part within the support of the specific university research.

\section{References}

[1] ROSAT, D.V., ROSAT, A.V., DIMATHIA, D.P. (2004). Blow Moulding Handbook, pp. 237-243. Hanser Gardner Publications, Munich, Germany.

[2] TAN, S.B., HORNSBY P.R., MCAFEE M.B., KEARNS M.P., MCCOURT M.P. (2011). Internal Cooling in Rotational Molding - a Review. In: Journal of Polymer Engineering and Science, Vol. 51, pp. 1683-1692. Wiley Online Library.

[3] HUNKAR, D.B. (1973). Cooling Blow -Molded Bottles from the Inside Out. In: Journal of Plastic Engineering. Vol. 29, pp. 25-27. Wiley Online Library.

[4] STIPSITS, B. (1993). Using $-30^{\circ} \mathrm{C}$ Internal Cooling Air to Achieve Faster Extrusion Blow Molding Machine Cycle Via the CAC - Compressed Air Cooling System. In: 9th Annual High Performance Blow Molding Conference, pp. 253-262. New Jersey, USA

[5] MICHAELI, W., BRUMER, T. (2007). Reduction o Cooling Time by Using Atomized Water in Blow Molding. In: Proceedings of Society of Plastics Engineers Annual Technical Conference, ANTEC 2007. Vol. 4, pp. 2137-2141. Ohio, USA.

[6] JORG, CH. (2006). Carbon dioxide cooling method may take the waiting out of plastic parts. In: Journal of Automotive Engineering, pp. 40-41. Loughborough University, UK. 